\title{
DEL SOBERANO A LA SOBERANÍA. SADE Y LA REALIZACIÓN DE LA LIBERTAD ABSOLUTA
}

\author{
Bruno Grossi \\ Universidad Nacional del Litoral \\ Consejo Nacional de Investigaciones Científicas y Técnicas \\ brunomilan@hotmail.com
}

\begin{abstract}
Resumen: Hay en Sade una heterodoxa teoría de la literatura. Es fama que su obra no desdeña la reflexión sobre Dios, el alma, la naturaleza, la política, la ley o el deseo, pero todas ellas parecieran tener como fin último una concreción formal al interior de la ficción que cuestiona y problematiza la pertinencia de tales conceptos en su relación pragmática con el exterior. Para ello nos interesa revisar una serie de textos no ficcionales escritos por el Marqués que iluminan o dan una nueva perspectiva a su obra, en tanto problematizan de raíz la imagen de ficciones absolutas $O$ puras, restituyéndolas a su contexto inmediato de producción. De hecho, he allí nuestra hipótesis: existe en Sade una denegación con respecto a la Revolución Francesa, repulsa consciente que se desplaza, transformada a la obra. Mas no solo eso: la literatura misma, tal como es planteada teóricamente por el propio autor, pareciera hacerse eco de la soberanía conseguida en el plano general, pero también de sus límites, sus excesos, sus retracciones.
\end{abstract}

Palabras claves: Sade, Revolución Francesa, Soberanía, Historia de la novela.

\begin{abstract}
There is in Sade an heterodox theory of literature. It is well know that his work does not disdain the reflection on God, the soul, nature, politics, law or desire, but all of them seem to have as final aim a formal concretion within a fiction that questions and problematizes the relevance of such concepts in their pragmatic relationship with the outside. In this sense we are interested in reviewing a series of non-fictional texts written by the Marquis that illuminate or give a new perspective to his work, as they fundamentally discuss the image of absolute or pure fictions, restoring them to their immediate production context. In fact, this is our hypothesis: there is in Sade a denial with respect to the French Revolution, conscious rejection that moves, transformed to the work. But not only that: literature itself, as it is theoretically proposed by the author himself, seems to echo the sovereignty achieved in the general level, but also its limits, its excesses, its retractions.
\end{abstract}

Keywords: Sade, French Revolution, Sovereignity, History of the novel. 
Que una desconfianza necesaria no os abandone jamás, reflexionad sin cesar sobre los medios de conservar esta libertad, que no se adquiere sin que corran ríos de sangre y que sólo un instante puede arrebatar

Sade

\section{Ni chiste ni sistema}

Antes que una filosofía o una ética, hay en Sade una heterodoxa teoría de la literatura. Es fama que su obra no desdeña la reflexión sobre Dios, el alma, la naturaleza, la política, la ley o el deseo, pero todas ellas parecieran tener como fin último una concreción formal al interior de la ficción que cuestiona y problematiza la pertinencia de tales conceptos en su relación pragmática con el exterior. No otra parece estar diciendo Foucault cuando sostiene que "la verdad de la que habla Sade no es la verdad de lo que cuenta, es la verdad de sus razonamientos" (1970, p.128). Es la paradoja muchas veces señalada: quien se lo toma realmente en serio -intentando abstraer, descomponer y conceptualizar sus tesis- se engaña; quien lo subestima reduciéndolo a mero consumo pornográfico desatiende su importancia. Sólo aceptando en su justa medida su seria y voluptuosa estupidez puede comprenderse la profundidad de la que su obra es acontecimiento fundamental. Ni chiste ni sistema: reflexión sobre el ser de la literatura, su constitución, sus antecedentes, sus proyecciones, pero, antes que todo, una interrogación sobre lo extremo y a su vez lo fútil de sus posibilidades. Para ello nos interesa revisar

$N^{\circ}$ 9. Segundo Semestre de 2018 
una serie de textos no ficcionales (cartas públicas, proyectos políticos, textos teóricos) escritos por el Marqués que iluminan o dan una nueva perspectiva a su obra, en tanto problematizan de raíz la imagen de ficciones absolutas o puras (tal como se deja leer en los ensayos de Barthes, Sollers o Le Brun), restituyéndolas a su contexto inmediato de producción. De hecho, he allí nuestra hipótesis: existe en Sade una denegación con respecto a la Revolución Francesa, más precisamente con el Terror jacobino, en el que la repulsa consciente se desplaza, transformada a la obra. Mas no solo eso: la literatura misma, tal como es planteada teóricamente por el propio autor, pareciera hacerse eco de la soberanía conseguida en el plano general, pero también de sus límites, sus excesos, sus retracciones.

"La palabra libertad es el grito nacional" (1969, p.25) dice Sade en Carta de un ciudadano de París al Rey de los franceses (1791) y pareciera explicitar de ese modo uno de los problemas fundamentales del siglo XVIII. ¿Cómo afirmar en el terreno práctico la soberanía conseguida en el plano del intelecto? En este punto no resulta casual que las búsquedas políticas y estéticas se encuentren, se anuden y entren en conflicto: la revolución y la obra de Sade parecieran dos modos extrañamente afines de responder a dicha pregunta. De hecho, pueden entenderse como dos formas de gritos que, en el momento de su mayor paroxismo, allí donde la libertad absoluta parece al alcance mismo de la mano, terminan por trocarse en su contrario: la arbitrariedad, la violencia y la sumisión más radical. De dicha ambivalencia no resuelta está hecha nuestra modernidad. 


\section{La furia del desaparecer}

La historia del Terror jacobino ha sido magnánimamente descripta por Hegel, quizás porque el alemán percibió allí el clímax de la historia de occidente. Un momento de tal intensidad que no podía sino generar un repliegue éticopolítico: luego del éxtasis inevitablemente adviene la calma, las conciencias parecen admitir sus limitaciones y se ven en la necesidad de replantear nuevamente sus relaciones con la libertad, la moral y la política. Pero antes de todo ello interesa la formulación de Hegel en tanto ayuda a pensar un extraño modus operandi del periodo revolucionario: una tensión entre libertad y muerte que luego se volverá análogo en las obras de Sade. Es en este sentido que puede afirmarse que a partir del capítulo VI La fenomenología del espiritu (1807) puede ser leída como la aventura, ya no de la consciencia (o ya no solamente), sino de la libertad en sí del espíritu humano. A través de las diferentes figuras históricas, Hegel presenta cómo el individuo se desprende de la inmediatez que lo ligaba a la naturaleza, pero también del sometimiento, el desgarramiento interior y la superstición. Dicha aventura alcanza en la Revolución Francesa su máxima concreción, ya que al liberarse de las esencias espirituales que organizaban el todo, el mundo se vuelve, para la consciencia, algo simple y finalmente expresión inmediata de su voluntad. El hombre, extasiado, se eleva por lo tanto de la esfera que le había sido asignada y toma conciencia que la estructura social, antes mistificada, es resultado de sí mismo. Pero no es su voluntad en tanto representación, relegada a un tácito asentimiento como ocurría en el pasado, 
sino que "la voluntad realmente universal es la voluntad de todos los individuos como tales (...) de tal manera que cada cual hace todo siempre de un modo indiviso y que lo que brota como obrar del todo es el obrar inmediato y consciente de cada uno" (Hegel, 1807, p. 344). Su obra se convierte por lo tanto en la obra universal: jla Revolución! El hombre se vuelve consciente por vez primera de que su objeto es la realidad producida a través de la universalidad de la que forma parte: las leyes y el Estado ya no se le aparecen como algo distinto de él mismo. Sin embargo, en el intento de aunar todas esas voluntades singulares en una sola voluntad universal la obra fracasa. Al dividirse necesariamente en estamentos, la libertad universal del Estado se disocia nuevamente en sus miembros particulares. En cada acción del Estado la autoconciencia singular percibe que éste deja de ser una autoconciencia universal y por lo tanto no se reconoce en dicho obrar. "Allí donde el sí mismo es solamente representado e imaginario no es real, donde se halla representado por otro no es" (Hegel, 1807, p.346). Si la mediación entre lo universal y lo singular es lo que define la política, lo que resulta de esta "voluntad universal" escindida de los particulares es la absolutización que rompe con toda mediación ("the individual will fuses with the universal immediately, totally, without residue" [Comay, 2004, p. 384]). Se generan así dos situaciones complementarias y conflictivas que llevan a un cul de sac de la política: por un lado una singularidad, una facción determinada se proclama expresión indivisa de la voluntad universal, traicionando inevitablemente -al actuar- lo universal en sí y, por otro, la singularidad que se opone a la facción dominante es percibida 
como una amenaza a la voluntad general. "Los individuos singulares se convierten, todos, en sospechosos, es decir, potencialmente culpables de traición” (Gehri, 2007, p. 806). En nombre de la virtud y lo universal, se suprimen las individualidades, las diferencias que justamente conforman y daban sentido a lo universal. Es la paradoja del Terror: "ninguna obra ni acto positivos puede producir la libertad universal; a dicha libertad solo le resta un obrar negativo; es solamente la furia del desaparecer" (Hegel, 1807, p. 346). La guillotina se convierte en política de Estado.

A pesar de su entusiasmo inicial, y del prejuicio que nos hace intuir su rechazo absoluto a la monarquía y su emoción frente el derramamiento de sangre, la posición de Sade en torno a la revolución es cuanto menos ambigua. Si por un lado afirma que "soy antijacobino, los odio a muerte; adoro al Rey pero detesto los antiguos abusos" (1969, p. 19), por otro sostiene que "mis obras prueban que yo abogaba por el sistema actual mucho antes que los cañones que derribaron la Bastilla lo anunciaran al universo" (1969, p. 41). Amén de las contradicciones, lo que a Sade pareciera interesarle es cómo potenciar los alcances y las posibilidades de la soberanía, sin importarle finalmente demasiado el signo del régimen en cuestión. En este punto resulta interesante contrastar la crítica al flamante gobierno en el texto comunitario (del que formó parte) Idea sobre el modo de sancionar las leyes (1792) con aquello que Hegel sistematizó varios años después:

Los hombres simples, libres y vuestros iguales, en los cuales vosotros delegáis solo momentáneamente una parte de la soberanía, que no pertenece a nadie más que a 
vosotros, no pueden, bajo ningún concepto, poseer esa soberanía en más alto grado que vosotros. La soberanía es una, indivisible, inalienable; la destruís dividiéndola, la perdéis transmitiéndola (1969, p. 34)

Entre la decapitación de Luis XVI y la conformación de la Asamblea general, el individuo se enseñorea, ya no hay ley o norma social que regule desde arriba su accionar, sino que se sabe por vez primera dueño de su destino. De este modo la omnipotencia del monarca se transmigra, se subdivide en cada una de las singularidades: del soberano se pasa a la soberanía. Sin embargo, el momento del éxtasis debe eventualmente cristalizarse en la construcción racional del Estado. Ese instante extático es el que Sade quisiera no obstante hacer durar, ya que intuye que la política parlamentaria traiciona la soberanía conseguida. Ésta inevitablemente debe hipostasiarse (y por lo tanto perder aquello que la vuelve tal) en una individualidad para poder efectuarse: es el nuevo Uno universal. De pronto el sujeto que se había vuelto finalmente soberano de sí termina por confundirse con el soberano depuesto. En este punto Sade se pregunta: “¿Cómo pueden imaginar un Mandatario público que el sólo título de Representante del soberano pueda darle el mismo derecho que posee ese Soberano? ¿Cómo creen que la parte de soberanía que vosotros le confías, pueda alguna vez darles el derecho de alcanzar la otra?" (1969, p. 36). El esquema de poder se reproduce, aunque en algún punto es inclusive peor: los abusos actuales llevan la marca, ya no de la arbitrariedad divina, sino de la razón de Estado. No es en la política, se deduce, donde puede efectuarse la soberanía sin restricciones. En este punto 
resulta llamativo cómo en el pasaje de La Fenomenología de la Libertad absoluta al Terror puede verse de alguna manera representado aquello que Sade ejecuta en sus ficciones. Tiene y no tiene razón Bataille cuando afirma que "el sentido de la revolución no está dado en la obra de Sade; en ninguna medida se pueden reducir sus obras a la revolución" (1957b, p. 97). Si afirmamos la relación no es justamente a título de continuidad y solidaridad ideológica entre ambos; la analogía es, por el contrario, estructural. Es decir, si en el esquema de Hegel al Uno universal solo le queda como última instancia obrar negativamente para afirmar la libertad de manera absoluta, destruyendo a cualquier sospechoso, en Sade la literatura alcanza realmente su soberanía y libertad total sólo cuando se entrega a los actos más ignominiosos. De allí que si los jacobinos instalaron el culto a la Razón y el Ser supremo como un modo de suturar la ausencia y desvanecimiento de la divinidad, en Sade ese nuevo culto tiene un nombre distinto: literatura.

Mucho se ha dicho sobre la economía criminal que anima las novelas del Marqués, pero en este punto interesa menos la compleja estructuración que liga la muerte al goce, que aquello que el crimen dice de aquel que lo ejecuta. Es lo que intentó Blanchot ceñir: Sade plantea una igualdad de los seres, pero es, en definitiva, el derecho de disponer igualmente de todos los seres. De allí que la libertad sea el poder de someter a cada uno a sus deseos. La soberanía se afirma -como en Robespierremediante la negación, la supresión del otro, volviéndose paradójicamente dependiente de la víctima (1949, pp. 34-35). Siguiendo el razonamiento hegeliano de Blanchot y redoblando 
la apuesta, Bataille plantea a su vez que "en la cima, la negación ilimitada del otro es negación de sí mismo" (1957, p. 179). He allí el momento artificial, irrealizable de la ética sadeana: señala un exceso de la razón que sólo puede existir a precio de destruirnos. Sin embargo, Bataille rescata el momento de verdad que se halla en tal extremo, ya que en la negación de la realidad "se arriesga el fundamento sobre el cual descansa nuestra vida", permitiéndole al hombre "acceder a la mayor satisfacción voluptuosa, a la consumación del deseo más fuerte" (1957, pp. 174-175).

\section{Estética del vicio}

Frente a la moral sadeana uno no puede dejar de preguntarse aquello que Adorno se planteaba en torno a Kierkegaard: “¿Pero cómo habría de comportarse la persona moral si lo exterior estuviera bajo su poder o pudiera posesionarse de ese poder?" (1933, p. 63). Todo aquel que quiera extraer de Sade una ética se enfrenta inevitablemente con una barrera: la empiria; pero la soberanía sadeana es a su vez el deseo de sobrepasar dicha empiria. No otra pareciera ser la tesis de Bataille: "Nadie pretendería que la crueldad de los héroes de Justine y Juliette no deba ser radicalmente execrada", pero "¿sería posible evitar absolutamente la negación que es la finalidad de estos instintos?” (1957, p. 190). Sin embargo, flaca noción de empiria tendríamos si la redujéramos e hipostasiáramos a lo posible en un momento históricamente determinado. En este punto resulta necesario revisar la noción 
de praxis tal como puede ser problematizada por la literatura. De hecho, el propio Sade en Ideas sobre la novela (1799) parece señalar nuevos modos de afección e intervención de lo literario sobre lo empírico. Pero ello sólo puede acontecer vía una transformación radical de la imagen e historia de la literatura. De allí que en dicho ensayo el Marqués proponga una lectura de la tradición que -amén de una brevedad que lo lleva a ciertos esquematismos- comience por enfatizar ciertos aspectos ignorados en los textos del pasado. En este sentido, toda la historia parece leída, pensada y valorada desde un par binario caro a sus propias novelas: la virtud y el vicio. No parece casual que la genealogía de la novela se remonte por lo tanto a Arístides de Mileto. Poco importa que no se haya conservado ningún texto suyo, que Apuleyo en su Asno de oro haya dicho que "las producciones de Arístides eran licenciosas" (1970, p. 34) es suficiente para colocarlo en el origen del nuevo canon. De esos gestos está hecha la historia de Sade: frente a toda una tradición hegemónica que hizo de la novela la aventura de los movimientos del alma, aquí predominan los vaivenes contradictorios de la materia. De allí que la delicadeza, la mesura, la armonía y el amor sean subordinados a la maldad, la risa, la disonancia y el sexo.

El epicureísmo los Ninon-de-Leclos, de los Marion-deLorme, de los marqueses de Sevigné y de La Fare, de los Chaulieu, de los Saint-Evremond, en fin, de toda esta encantadora sociedad, que, de vuelta de las languideces del Dios de Citerea, comenzaba a pensar, como Buffon, «que no había otro amor más que el físico», cambió pronto el tono de las novelas; los escritores que aparecieron a continuación, sintieron que las soserías ya no divertían a un siglo pervertido por el regente, un siglo hastiado por las 
locuras caballerescas, de las extravagancias religiosas y de la adoración de las mujeres; y encontrando más sencillo divertir a estas mujeres o corromperlas, que servirlas o incensarlas, crearon acontecimientos, escenas, conversaciones más acordes con el espíritu del día; rodearon de cinismo las inmoralidades, y si no instruyeron al menos gustaron (1970, p.42)

A pesar de su contemporaneidad, hay en Sade una idea muy propia de su siglo: la novela debe tener un fin educativo. De la pregunta formalista por las reglas de la novela se pasa por lo tanto a la pregunta irónica por la utilidad: “¿Para qué sirven? Hombres hipócritas y perversos; pues sois los únicos en hacer esta ridícula pregunta; sirven para describiros" (1970, p. 49). En este sentido la novela es tanto un cuadro de las costumbres seculares, como un desvelamiento progresivo de los caracteres ocultos de los hombres. La metáfora del reflejo, sí, pero también la de la máscara: una vez levantada la fachada con la que sobrellevamos la vida en sociedad aparecen una serie de atributos difíciles de aceptar aun para nosotros mismos. La novela oficiaría por lo tanto como un proceso de desmascaramiento y concientización del sujeto: pondría en la superficie aquellos vicios que la razón negó sistemáticamente para constituirse y que solo apareció de forma fragmentaria en el pasado. Sin embargo, los fines documentales y psicológicos de la novela son sólo la antesala de su verdadero aporte histórico: la invención de caracteres nuevos.

Son Richardson y Fielding quienes nos han enseñado que el estudio profundo del corazón del hombre, verdadero 
laberinto de la naturaleza, es lo único que puede inspirar al novelista, cuya obra debe hacernos ver al hombre, no solamente como es, o como se muestra, que este es deber del historiador, sino tal como puede ser, tal como deben convertirle las modificaciones del vicio, y todos los impulsos de las pasiones (...) pues cuando la virtud triunfa, siendo las cosas como deben ser, nuestras lagrimas se secan antes de derramarse; pero si después de las más rudas pruebas, vemos finalmente a la virtud fulminada por el vicio, indefectiblemente nuestras almas se desgarran, y habiéndonos la obra emocionado excesivamente, habiendo, como decía Diderot, ensangrentado nuestros corazones al revés, debe producir el interés que es el único en asegurar los laureles (1970, pp. 44-45)

Es en el vicio, es decir en el instante extático en el que es fulminado el principio de realidad encarnado por la virtud, donde el sujeto comprueba su verdadera naturaleza. Es un giro copernicano de la historia de la novela. Si bien nunca faltaron en el pasado momentos de terror, de crueldad, de locura, de voluptuosidad sexual, de obsesiones desfigurantes, de desencadenamiento irracional de las pasiones, estos eran finalmente recuperados por la moral imperante. El mal servía luego de un complejo rodeo hecho de perversa identificación y luego de rápida neutralización en la conciencia- para hacernos abrazar más fervorosamente el bien. El vicio aparece ahora por lo tanto integrado en una nueva economía de sentido. Poco importa que luego ante la censura Sade matice su afirmación haciendo un elogio -muy batailleano- de la virtud (el vicio sólo puede ser disfrutado si la virtud se mantiene estoicamente en su pureza), (1970, p. 83), el vicio aparece no obstante como aquello que pone definitivamente en movimiento al hombre. 
Es lo que permite a Sade evadirse del realismo imperante y redefinir los criterios con los cuales pensábamos la literatura. Su planteo no deja de ser explícito: la virtud está del lado de lo fáctico, de la cristalización del sentido, de la vida agrietada. En términos de Rancière: de lo que se aleja la nueva novela sadeana es de un régimen antiguo que establecía una relación reglamentada entre modos de hacer y modos de ser (2004, p. 16). De allí el rechazo de Alexander-Louis Villetorque a los cuentos del marqués aduciendo su descarada falsedad y la desviación con respecto a los principios eternos de la naturaleza humana (en Sade 1970, p. 72). Antes que una naturaleza estática, dada de una vez y para siempre, es por el contrario el misterio (el laberinto) que ella es lo que la novela debe interrogar.

\section{Soberanía del arte}

El vicio no significa aquí otra cosa que el modo en el que la naturaleza (humana, social) es, puede y debe ser desgarrada. La novela es el medio privilegiado para la transformación de las conciencias, pero eso sólo puede ocurrir cuando se tensan los límites de lo real. Es lo que plantea Sade cuando sostiene que "una vez hecho tu esbozo, trabaja ardientemente en extenderlo, pero sin recluirte en los límites que de entrada parece prescribirte; con ese método te convertirás en magro y frío; lo que queremos de ti son arrebatos, no reglas" (1970, p. 52). Si, tal como sostiene Hegel, en el acto de determinar, de

establecer límites estos ya se encuentran efectivamente 
superados, Sade vuelve evidente la arbitrariedad de las prohibiciones que toda conciencia virtuosa (ya sea en el plano de la literatura o de la moral) eleva a condición universal. Sade parece postular por lo tanto cómo la literatura trabaja dialécticamente sobre dichos límites: ya no una serie de reglas que armonizan la materia artística a la materia vivencial, sino una forma que hace del arrebato su lógica inmanente.

Antes inclusive que el romanticismo, ya en Sade puede leerse por lo tanto el ejercicio de la literatura como el autocuestionamiento de su propia ontología. Sin embargo, comparadas con el Tristram Shandy de Sterne o El sobrino de Rameau de Diderot las novelas del Marqués son relativamente convencionales: la libertad se supedita finalmente a la cantidad de placer y crueldad que es posible representar. En Sade la cuestión del límite implica y sobrepasa a la propia literatura: el exceso formal supone un exceso moral. Las vanguardias históricas parecen nacer y operar según esta segunda vía: es la economía de la transgresión que funda tempranamente Sade. De hecho, cuando sostiene que "a medida que los gustos se hastían, que los espíritus se corrompen, que se está cansado de novelas, de comedias, de cuentos, es preciso necesariamente presentar cosas más fuertes, si se quiere triunfar" (1970, p. 64), ya parece intuir la dinámica futura del arte del siglo XX: la dialéctica de exceso y naturalización del mal en la conciencia del lector/espectador burgués. ¿No es justamente el proceso que sus novelas narran? El aumento exponencial de los excesos, tal como pueden leerse por ejemplo en Las 120 jornadas de Sodoma, es el resultado de una nueva frialdad moderna que ve como progresivamente sus sentidos 
comienzan a adormecerse, que ya nada parecen bastarle, que debe multiplicar al infinito sus vicios. La explicitez se convierte en norma, el rebasamiento moral en precondición. Es ya, en suma, la autonomía del arte, es decir, la escisión radical entre estética y ética. Tensión entre una multiplicación irrestricta del placer en la que intuimos una verdad que querríamos retener y unos medios para alcanzarlo que no podemos sino problematizar. No parece casual en este punto que la libertad absoluta del texto sadeano parezca hacerse eco de la libertad conseguida en el terreno político. Sin embargo, las promesas de una soberanía ilimitada tras el fin de la monarquía parecen agotarse rápidamente: la horca es el destino de toda individualidad que exprese una voluntad contraria a la voluntad universal enajenada. La imposibilidad de hacer valer la soberanía en el terreno público genera por lo tanto un repliegue al ámbito privado de la estética. En este punto cobra sentido lo que dice Adorno:

El carácter doble del arte en tanto que autónomo y en tanto que fait social se comunica sin cesar a la zona de su autonomía. En esa relación con la empiria, las obras de arte salvan, neutralizado, lo que una vez los seres humanos experimentaron literal y completamente en la existencia y lo que el espíritu expulso de esta (...) Su propia tensión es acertada en relación con las tensiones de afuera (1970, p. 15)

Cuando Foucault afirma que "gracias a la escritura [de Sade] el deseo se ha convertido, ha entrado definitivamente en el mundo de la verdad total, absoluta e ilimitada y sin impugnación exterior posible" (1970, p. 142) uno no puede 
menos que asentir primero y desconfiar después por un cierto voluntarismo teórico de su parte. Es verdad que el deseo, gracias a Sade, ha conocido una verdad inédita e ilimitada, pero también que el exterior impone un límite cierto a aquello leído. El texto sadeano es la felicidad de lo que le dice la verdad al mundo y la mentira de aquello que ya no puede realizarse. El texto retiene el placer negado por una sociedad represiva y falsamente armónica, pero lo hace a precio de sacrificarlo en la vida real. La libertad al interior del arte invierte la falta de libertad en el exterior. De allí la vinculación señalada con la revolución: la secularización naciente libera a los individuos por derecho pero todavía no de hecho. En este punto en la censura efectiva al Marqués se muestra paradójicamente las similitudes con aquello que se dejó atrás. A propósito de la dinámica de heteronomía-autonomía, Rothko sostiene

La mayoría de las sociedades del pasado exigían del artista que reflejara los conceptos de verdad y moralidad de la época (...) para que al artista se le permita practicar su arte, tenía que someterse a estas reglas o aparentar sumisión a ellas. Podría decirse que sucede lo mismo con los artistas de hoy en día; que el mercado, al otorgar o privar al artista de sus medios de subsistencia, ejerce la misma presión. Sin embargo, existe una diferencia vital: las civilizaciones que hemos mencionado anteriormente tenían el poder temporal y espiritual de exigir que se cumplieran sus expectativas sin dilación. Las llamas del infierno, el exilio y, como telón de fondo, la hoguera, eran correctivos en caso de que la persuasión fallara. Hoy en día el poder coercitivo lo ejerce el hambre (2004, p. 46) 
Sade se encuentra paradójicamente en el umbral entre ambos momentos. Las condiciones materiales se han transformado a tal punto que su obra es la de aquel que se sabe una conciencia libre y soberana, pero las limitaciones sociales existentes le cuestan todavía su libertad empírica. Que su obra exista, aunque sea fragmentada, desorganizada, censurada, perdida, conservada, revela la tensión irresuelta entre el interior y el exterior, lo pensable y lo decible, lo factible y lo imposible. En Sade parece estar contenida y llevada a su extremo la dialéctica inmanente de toda obra de arte autónoma. Es en este punto que puede afirmarse que su obra es estrictamente realista (a pesar de los medios muchas veces inverosímiles que utiliza): "los antagonismos irresueltos de la realidad retornan en las obras de arte como los problemas inmanentes de su forma" (Adorno, 1970, p.15). Sade es, en este sentido, la mala conciencia de la revolución.

\section{Referencias Bibliográficas}

Adorno, T. (1933). Kierkeegard. Madrid: Akal, 2006. (1970). Teoría estética. Madrid: Akal, 2011.

Bataille, G. (1957). El erotismo. Buenos Aires: Tusquets, 2009. (1957). La literatura y el mal. Barcelona: Nortesur, 2010.

Blanchot, M. (1949). Sade y Lautremont. Buenos Aires: Del mediodía, 1967. 
Comay, R. (2004). "Dead right: Hegel and the Terror" en South Atlantic Quarterly, 103 (2-3). pp. 375-395.

Foucault, M. (1970). La gran extranjera. Buenos Aires: Siglo XXI, 2015.

Gehri, G. (2007). "Hegel y el Terror; la Revolución francesa como figura fenomenológica" en Miscelánea Comillas, 65, (127). pp. 801-812.

Hegel. G (1807). La fenomenología del espíritu. Buenos Aires: FCE, 2015 .

Sade, D (1970). Ideas sobre la novela. Barcelona: Anagrama.

(1969). Carta de un ciudadano de París. Rosario: Aries.

Rancière, J. (2004). El malestar en la estética. Buenos Aires: Manantial.

Rohtko (2004). La realidad del artista. Madrid: Síntesis. 